BMJ Paediatrics Open

\title{
Access to paediatric palliative care in children and adolescents with complex chronic conditions: a retrospective hospital-based study in Brussels, Belgium
}

Marie Friedel (D) , ${ }^{1,2}$ Aurélie Gilson, ${ }^{1}$ Dominique Bouckenaere, ${ }^{3}$ Bénédicte Brichard, ${ }^{3,4}$ Christine Fonteyne, ${ }^{3,5}$ Thomas Wojcik, ${ }^{3}$ Etienne De Clercq, ${ }^{1}$ Alain Guillet, ${ }^{6}$ Alaa Mahboub, ${ }^{1}$ Magali Lahaye, ${ }^{1,7}$ Isabelle Aujoulat ${ }^{1,8}$

\section{ABSTRACT}

Background Paediatric complex chronic conditions (CCCs) are life-limiting conditions requiring paediatric palliative care, which, in Belgium, is provided through paediatric liaison teams (PLTS). Like the number of children and adolescents with these conditions in Belgium, their referral to PLTs is unknown.

Objectives The aim of the study was to identify, over a 5-year period (2010-2014), the number of children and adolescents ( $0-19$ years) living with a CCC, and also their referral to PLTs.

Methods International Classification of Disease codes (ICD-9) corresponding to a CCC, as described by Feudtner et al, and national registration numbers were extracted from the databases of all hospitals $(n=8)$ and PLTs $(n=2)$ based in the Brussels region. Aggregated data and pseudonymised national registration number were transmitted to the research team by a Trusted Third Party (eHealth). Ages and diagnostic categories were calculated using descriptive statistics.

Results Over 5 years (2010-2014) in the Brussels region, a total of 22721 children/adolescents aged 0-19 years were diagnosed with a CCC. Of this number, 22533 were identified through hospital registries and 572 through PLT registries. By comparing the registries, we found that of the 22533 children/adolescents admitted to hospital, only $384(1.7 \%)$ were also referred to a PLT.

Conclusion In Belgium, there may be too few referrals of children and adolescents with CCC to PLTs that ensure continuity of care.

\section{Check for updates}

(c) Author(s) (or their employer(s)) 2019. Re-use permitted under CC BY-NC. No commercial re-use. See rights and permissions. Published by BMJ.

For numbered affiliations see end of article.

Correspondence to Marie Friedel; marie.friedel@ uclouvain.be

\section{INTRODUCTION}

A complex chronic condition (CCC) "can be reasonably expected to last at least 12 months (unless death intervenes) and to involve either different organ systems or one organ system severely enough to require specialty paediatric care and probably some period of hospitalisation in a tertiary care centre". Life-threatening diseases are diseases which might shorten life expectancy. Life-limiting

\section{What is known about the subject?}

The number of children and adolescents facing complex chronic conditions is increasing.

- Complex chronic conditions are considered life limiting/life threatening.

- A list of complex chronic conditions linked to International Classification of Diseases codes is available.

\section{What this study adds?}

Over 5 years (2010-2014), 22721 children/adolescents aged $0-19$ years were diagnosed with a complex chronic condition through databases from eight hospitals and two paediatric liaison teams located in Brussels, Belgium.

Children/adolescents with complex chronic conditions admitted to a hospital are rarely referred to paediatric liaison teams in Brussels.

conditions are defined as health conditions with no reasonable hope of cure and that will ultimately lead to early death. ${ }^{2}$ A complex chronic condition is sometimes life limiting and often life threatening and might require paediatric palliative care at different stages. ${ }^{3}$ It is not easy to establish the number of children living with a life-limiting condition. ${ }^{4}$ In England, Fraser et a $a \tilde{l}$ found a prevalence of $3.2 \%$ of children (0-19 years) living with such a condition, and Jarvis et al found in the CHiSP study conducted in Scotland from 2009 to 2014 that 20436 children and young people ( $0-25$ years) were identified as having life-limiting conditions. ${ }^{6}$

Many other studies relied on death registries to estimate the number of children with CCCs. A Canadian study found that $26.8 \%$ of 
the 4199 children aged 0-19 years who died between 1997 and 2001 had had a CCC, and that $48 \%$ had died in the first 6 months of life. ${ }^{7}$ A quarter of the 11194 children aged 1-19 years who died in France between 2005 and 2008 had a CCC. ${ }^{8}$ A European multicentre study showed that a third of the 299 children aged 1-17 years who died in Belgium in 2008 (35.8\%, $\mathrm{n}=107)$ had had a CCC. ${ }^{9}$

However, it is known that relying on death record data only does not reflect the real number of children with a life-limiting or life-threatening condition, and therefore it is recommended to use routine health data. ${ }^{10}$

Paediatric Palliative Care for children/adolescents in Belgium is provided through five paediatric liaison teams (PLTs), each of which is attached to a university hospital. The mission per centre is to ensure continuity of care through all care settings (in and out of hospital) for children with life-limiting or life-threatening conditions, including CCCs. Funding of these PLTs has been integrated into the Belgian Health coverage since $2010 .^{11}$ In 2016, the legislation was modified to state that palliative care should not be restricted to end-of-life care but should be provided progressively according to patients' needs and wishes, independently of life expectancy. ${ }^{12}$

It is not known how many children and adolescents live with CCCs in Belgium or what access they have to paediatric liaison care teams. Hypothesising that many children living with CCCs are not referred to a PLT, we wished to establish (1) the number of children/adolescents (0-19 years) with CCCs and (2) the percentage referred to PLTs in Belgium's Brussels Region, which has eight hospitals with a paediatric unit and two PLTs.

\section{METHODS \\ Design}

This retrospective hospital-based study used existing health data collected from all the hospitals in Brussels with paediatric units $(\mathrm{n}=8)$ and from all the PLTs based in Brussels ( $\mathrm{n}=2$ ).

There were three reasons for choosing the 5-year study period, which started in 2010 and ended in 2014. First, when the official funding of paediatric liaison care teams started in 2010, data registration became mandatory. Second, in 2015, the International Classification of Diseases, Ninth Revision (ICD-9) classification changed in Belgium to ICD-10. Third, the only published study on the number of children referred to PLTs in Belgium was based on the same 5 -year period. ${ }^{13}$

\section{Patient selection}

For this study, we selected all children/adolescents (0-19 years) diagnosed with a CCC and admitted between 1 January 2010 and 31 December 2014 to one of the eight hospitals in Brussels with a paediatric unit. Independently of their diagnosis, we also selected all children/adolescents (0-19 years) referred to the two PLTs based in Brussels, knowing that these two PLTs cover the eight hospitals in Brussels.

\section{Data collection}

We used the methods described by Feudtner $e t a l^{14}$ based on the ICD-9 codes ${ }^{15}$ linked to a CCC.

All ICD-9 codes corresponding to a CCC and linked to a national register number were extracted from existent hospital databases issued from a mandatory 'minimal hospital synthesis' (Résumé Hospitalier Minimum; RHM), an anonymised registration system for administrative, medical and nursing data. ${ }^{16}$ We created a standardised electronic file in Excel that included the variables and formulae requested, maximising the homogeneity of the data collected by the data managers. These files were sent to the data managers of each of the eight participating hospitals and to the two PLTs.

Anonymously, as dictated by the Sectoral Committee for Social Security and Health, the data managers at the eight hospitals and two PLTs sent national registration numbers and aggregated data to a Trusted Third party (eHealth),${ }^{17}$ which pseudonymised the national registration numbers, and sent the aggregated data to the research team for analysis. Knowing the pseudonymised national registration numbers of each children/adolescent, we were able to compare databases from the hospitals with those from the PLTs.table 1

Figure 1 presents the data-flow process used for this study.

\section{Data analysis}

Figure 2 shows the flowchart of the process leading to the definitive database.

Ages and diagnostic categories were calculated using descriptive statistics with program $\mathrm{R}$ software (V.3.3.2). Results were discussed in three meetings with the steering committee of the Brussels Pluralist Federation for Palliative and Continuing Care, consisted of DB, TW, BB and CF. ${ }^{18}$

\section{Patient and public involvement}

This study was commissioned by the Brussels Regional Platform for Palliative Care, called the Brussels Pluralist Federation for Palliative and Continuing Care (FBSP), who wanted to estimate the number of children and adolescents with complex chronic conditions and their referral to specialised paediatric palliative care teams called PLTs. The FBSP (DB, TW, BB, CF) were involved in the design of the study and in the interpretation of the results. Dissemination of these results was initiated and coordinated by the FBSP, through a public conference addressed to paediatricians and a special public seminar on paediatric palliative care hold at the Brussels Francophone Parliament on 6 December 2018, at the invitation of Julie de Groote, president. ${ }^{19}$

\section{RESULTS}

Over the 5-year period, a total of 22721 children and adolescents aged 0-19 years with a CCC were identified through the registries of the hospitals $(n=8)$ and PLTs $(n=2)$ based in Brussels, Belgium. 
Table 1 Overview of the variables requested, received and the limitations imposed by the sectoral Committee for Social Security and Health (CSSSS)

\section{Variables requested of data} managers

National registration number

Principal and secondary diagnosis of a complex chronic condition

Limitation imposed by CSSSS

Pseudonymisation

Principal diagnosis aggregated to 1 of the 9 categories; secondary diagnosis aggregated to 1 of the 9 categories

\begin{tabular}{lll}
$\begin{array}{l}\text { Dates of admission to and } \\
\text { discharge from hospital }\end{array}$ & Day/month/year & $\begin{array}{l}\text { Day/month/year of admission day/month/ } \\
\text { year of discharge }\end{array}$ \\
$\begin{array}{ll}\text { Date of birth (day/month/year) } \\
\text { Gender }\end{array}$ & Aggregated to six categories & $\begin{array}{l}0-11 \text { months, 1-4 years, 5-9 years, 10-15 } \\
\text { years, 16-19 years, >20 years }\end{array}$ \\
\hline Postal code of residence & $\begin{array}{l}\text { Male/female/unknown/changed } \\
\text { Aggregated to one of the 13 regions in } \\
\text { Belgium }\end{array}$ & $\begin{array}{l}\text { Male/female } \\
\text { 13 regions in Belgium; unknown }\end{array}$ \\
$\begin{array}{ll}\text { Nagregated to one of the six regions defined } \\
\text { by WHO }\end{array}$ & 6 regions \\
Insurance status & Insured or not & Insured or not \\
\hline
\end{tabular}

Of those, 22149 children and adolescents aged 0-19 years with a CCC were admitted in one of the eight hospitals but were not referred to a PLT, and only 384 $(1.7 \%)$ children and adolescents were both admitted to a hospital and referred to a PLT.

Regarding geographical factors, we found that $40.3 \%$ $(n=9081)$ of the children/adolescents with CCC admitted to one of the eight hospitals were resident in the Brussels region, whereas $45.2 \%(n=10$ 195) lived elsewhere. Data were unknown for $14.6 \%(n=3257)$. Only $1.05 \%(n=95)$ of all children residing in Brussels, diagnosed with a CCC and admitted to a hospital in Brussels $(n=9081)$ were referred to one of the two PLTs based in Brussels.
Variables received by the research team Pseudonymised code

Cancer; digestive disease; cardiovascular disease; haematological/immunological disease; neurological disease; respiratory disease; urinary disease; congenital/genetic disease; metabolic disease

Day/month/year of admission day/month/ year of discharge

0-11 months, $1-4$ years, 5-9 years, 10-15 years, $16-19$ years, $>20$ years

le/femal
When we looked at the type of diseases found for the children admitted to hospitals ( $\mathrm{n}=22$ 533), labelled with a CCC and over a 5-year period, our results showed that cardiovascular disease was the most common underlying condition $(28 \%$; $\mathrm{n}=6310)$, followed by neurological conditions $(18 \% ; \mathrm{n}=4125)$ and cancer $(14 \% ; \mathrm{n}=3011)$. These figures contrast with the type of diseases found in the PLT databases $(n=572)$, where diseases of the nervous system predominated $(21 \%, \mathrm{n}=121)$, followed by cancer $(17 \%, \mathrm{n}=98)$ and cardiovascular disease $(10 \%, \mathrm{n}=60)$.

We also found the following: that nearly one-third of the children were aged under 1 year $(30 \% \mathrm{n}=6692)$, and that $71 \%(\mathrm{n}=276)$ of all registered hospital deaths

Fig. 1: Data-flow process

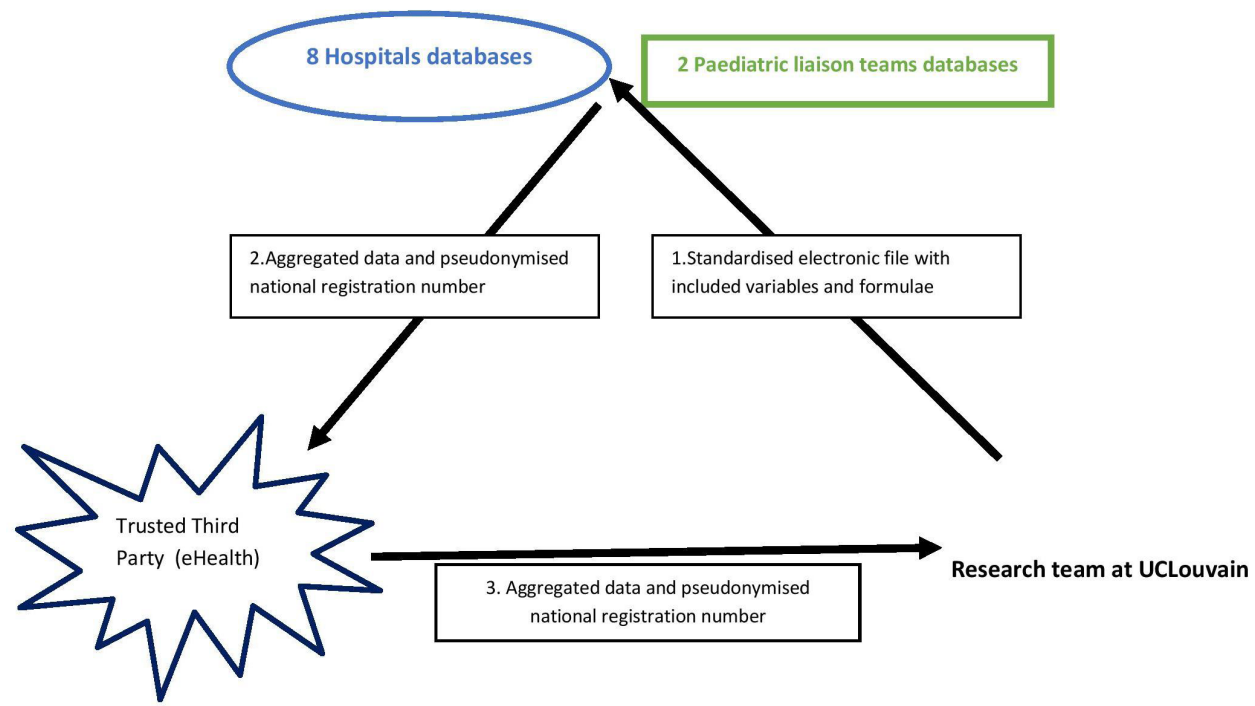

Figure 1 Data-flow process. 
Figure 2. Flowchart of the process leading to the definitive database

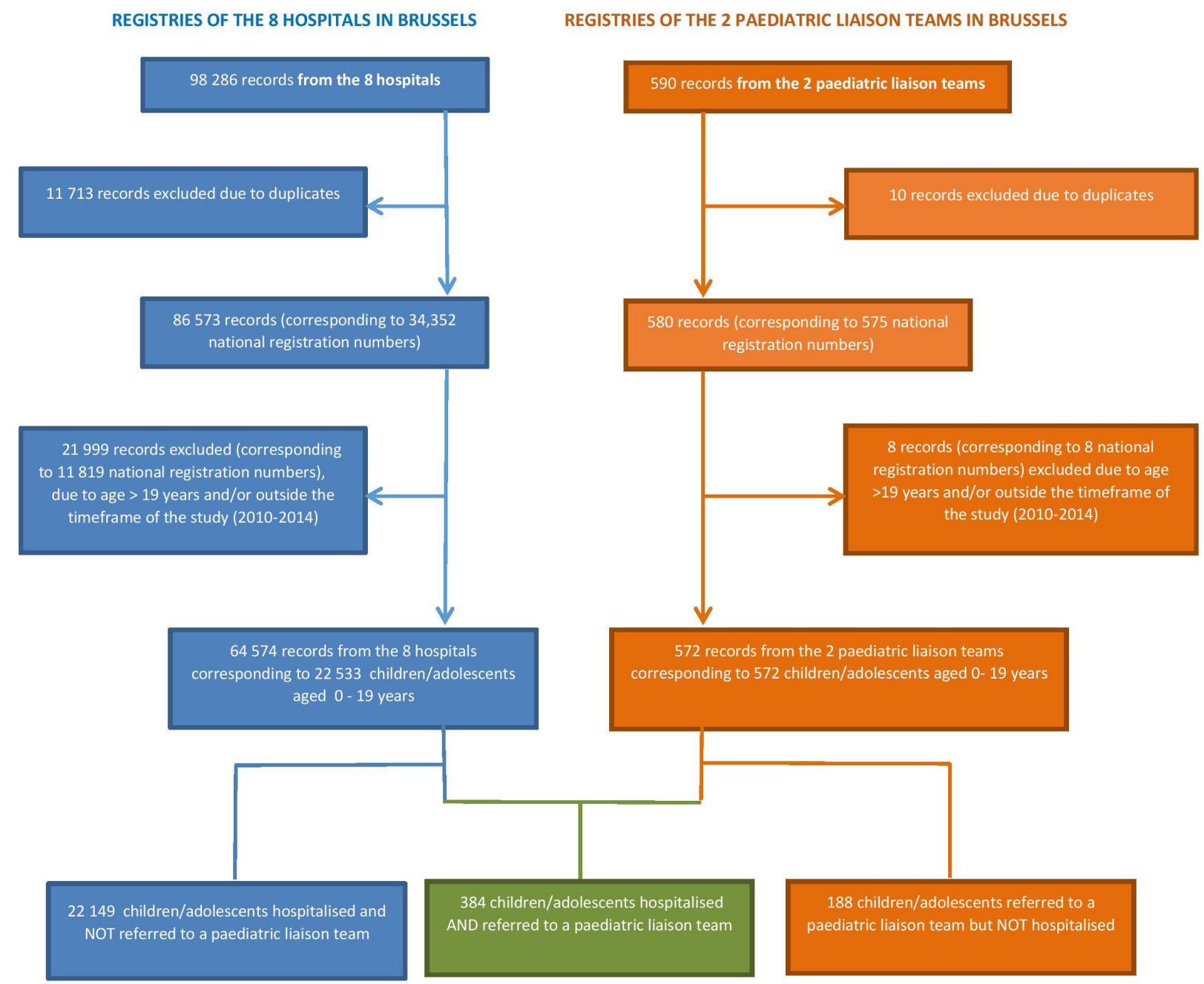

Figure 2 Flowchart of the process leading to the definitive database.

( $\mathrm{n}=390 ; 0-19$ years) involved children with cardiovascular diseases who had died before the age of 1 .

Of all children admitted to hospital $(n=22533)$ in this period, $87 \%$ had a European nationality $(\mathrm{n}=19$ 613), $7.5 \%$ an African nationality $(\mathrm{n}=1690)$ and $1.3 \%$ an Asian nationality $(\mathrm{n}=298)$. The nationality of $2.7 \%(\mathrm{n}=600)$ was unknown.

Of all the children admitted to hospital with a CCC in this period, 6.3\% ( $\mathrm{n}=1428)$ had no insurance and/or received public assistance (CPAS).

Table 2 shows the number of children/adolescents identified in hospital and PLT databases from 2010 to 2014 according to gender, categories of age and disease, frequency of hospital admissions and length of stay.

\section{DISCUSSION}

We identified a large number of children with a CCC who had been admitted to hospitals in Brussels during the study period ( $\mathrm{n}=22533$ ). However, only a very small percentage $(1.7 \% ; n=384)$ of those had been referred to one of the two PLTs covering the same region at the same period (2010-2014).

The high proportion of children with CCC who are not referred to PLTs, especially those under 1 year, may be partially explained by the fact that many of these children die before they are discharged from hospital, but also because neonatal palliative care is overlooked in Belgium. Furthermore, a previous study conducted by Friedel $e t$ al indicated that from all children followed up annually by PLTs at a nationwide level $(\mathrm{n}=721)$, a high proportion of home deaths $(51 \%)$ occurred for all children who died $(\mathrm{n}=85)$ and therefore were neither registered in death hospital databases. ${ }^{13}$ The maximum number of 721 children followed up annually by the five PLTs in Belgium invalidates therefore the hypothesis according which the high number of patients with a CCC attending Brussels hospitals ( $\mathrm{n}=22$ 533) may have been referred to PLTs outside Brussels. 
Table 2 Number of children/adolescents identified in the databases of hospitals and paediatric liaison teams from 2010 to 2014 according to gender, categories of age and disease, and hospital admissions

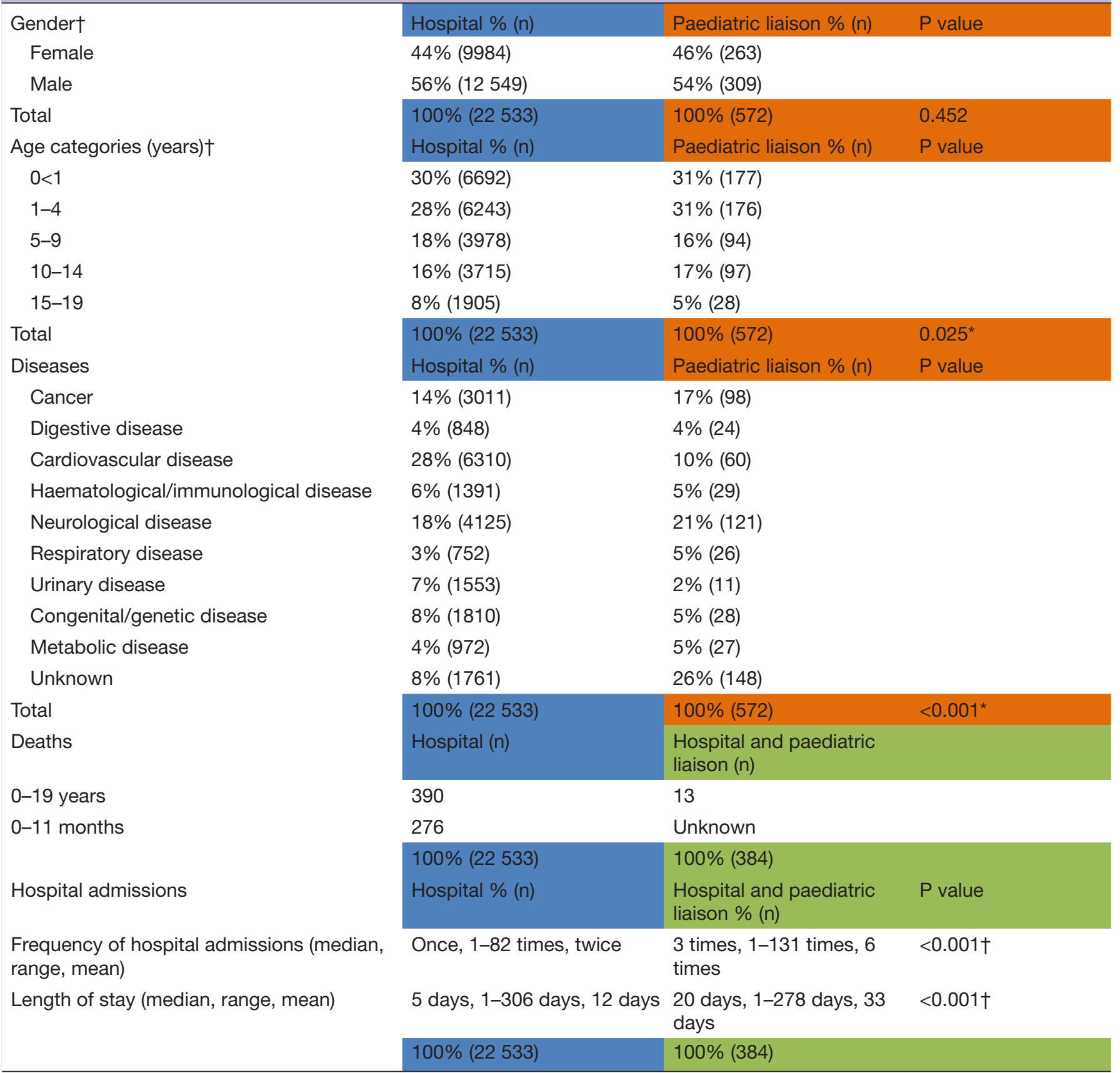

${ }^{*} \mathrm{p}<0.05$.

t $\chi^{2}$ test.

While the number of children with cardiovascular diseases is higher than in other studies, ${ }^{50}$ the other studies in question used a different definition of life-limiting and life-threatening conditions, and therefore different ICD-10 codes. The aggregation into diagnostic groups in the UK-based studies also featured many cardiovascular conditions in the congenital anomalies group. Moreover, two of the eight hospitals included in our study are university hospitals known for their high number of highly specialised paediatric cardiological activities which could explain the high number of children suffering from cardiovascular conditions found in our results.

This study has four main limitations. First, according to ICD-9, which was published in 2001 on the basis of paediatric deaths, the rapid progress of medical therapeutics may be causing certain CCCs to evolve, which may therefore require fewer hospital admissions. Although reference to another classification, such as ICD-10, may have yielded different results, the registration system in use during the study period made this impossible. Second, due to the obligation imposed on us to receive aggregated 
data-that is, only the categories of diagnostics and not the precise disease codes-we did not receive detailed information on the types of disease in the children included in this study. Third, the mandatory registration of data starting for PLTs only in 2010 did not systematically register diseases under the ICD classification system, which led to missing data in our study. Finally, as many people were involved in data handling, human errors could not be ruled out.

Nevertheless, with regard to the conceptual, methodological, logistic, ethical and legal complexities inherent to this study, our results provide useful data on the extent of the problem regarding the number of children with CCCs in Belgium. To our knowledge, this is the first multicentre study in Belgium to estimate the number of children and adolescents with a CCC and to identify the proportion who are followed up by a PLT. Having included all the eight hospitals in Brussels (two of which were university hospitals with over 900 beds) and two of the five national PLTs in Belgium, we believe that it will be possible to extrapolate our results to the national level.

\section{CONCLUSION}

Even though it is the mission of the two PLTs to ensure continuity of care between the hospital and the homes of children with a serious illness, we found that only a very small percentage of the 22533 children with a chronic complex disease who were identified over a 5 -year period $(1.7 \%, \mathrm{n}=384)$ admitted to a hospital were followed up by one of the city's two PLTs. Our results suggest that the number of referrals of such children and adolescents to a PLT in Belgium is probably insufficient or is reserved for the most complex situations. Further studies are needed to estimate the type of care needed by children and adolescents facing complex chronic conditions but also to better understand why those patients are insufficiently referred to paediatric liaison teams.

\author{
Author affiliations \\ ${ }^{1}$ Institute of Health and Society, Université catholique de Louvain, Brussels, Belgium \\ ${ }^{2}$ Nursing Department, Haute Ecole Léonard de Vinci Parnasse-ISEI, Brussels, \\ Belgium \\ ${ }^{3}$ Fédération Bruxelloise Pluraliste de Soins Palliatifs, Brussels, Belgium \\ ${ }^{4}$ Paediatric Hematology-Oncology and Paediatric liaison team Interface Pédiatrique, \\ Cliniques universitaires Saint-Luc, Brussels, Belgium \\ ${ }^{5}$ Paediatric liaison team Globul'home, Hôpital universitaire des Enfants Reine \\ Fabiola, Brussels, Belgium \\ ${ }^{6}$ Statistical Methodology and Computing Service (SMCS), Institute LIDAM, \\ Université catholique de Louvain, Louvain-la-Neuve, Belgium \\ ${ }^{7}$ Paediatric Haematology/Oncology, Cliniques universitaires Saint-Luc, Brussels, \\ Belgium \\ ${ }^{8}$ Faculté de Santé Publique, Université catholique de Louvain, Brussels, Belgium
}

Acknowledgements We would like to thank the medical directors of the eight hospitals who agreed to participate in this study: Centre hospitalier Interrégional Edith Cavell, Centre hospitalier universitaire Saint-Pierre, Clinique Saint-Jean, Cliniques universitaires Saint-Luc, Hôpital Érasme, Hôpitaux Iris Sud, Hôpital universitaire des Enfants Reine Fabiola and Universitair Ziekenhuis Brussel. We are especially grateful to all the data managers at these hospitals for their support in extracting the data: G Bouhy, K Pien, M Anthonis, G Bockstal, N Mbengo, C Beguin, A Kanfaoui, and P Kirkove. Similarly, we are very grateful for the collaboration of the chief nurses at the two paediatric liaison teams (G Hendrijckx and N Andersson at Globul'home, and C Tonon at Interface pédiatrique) and also to $\mathrm{N}$ Donnez at eHealth and A Audibert at IREC-UCLouvain. Finally, we sincerely thank Professor S Moniotte for his discussion of the preliminary results of a number of children with cardiovascular conditions, Dr R Hain for his comments on the interpretation of the results and Dr Lorna Fraser for her constructive comments on the final manuscript.

Contributors MF, AGi, DB, IA, ML, BB, CF and EDC designed the study and contributed to the analysis and interpretation of the data, and reviewed and revised the manuscript. IA supervised the data collection and analysis and critically reviewed the manuscript for important intellectual content. MF drafted the initial manuscript and coordinated the data collection and analysis. AGu and AM contributed to the data analysis. All authors approved the final manuscript as submitted and agree to be accountable for all aspects of the work.

Funding We would like to thank Fondation Contre le Cancer, which funded this study through a grant to Fédération Bruxelloise pluraliste de Soins palliatifs et Continus.

Competing interests None declared.

Patient consent for publication Not required.

Ethics approval The study was conducted in accordance with Belgium's legal and ethical requirements for the collection of personal data. Approval was obtained on 29 Feb 2016 from the Data Protection Authority and on 20 Sep 2016 from the Sectoral Committee for Social Security and Health (no. CSSSS/16/193). In addition, the Sectoral Committee for Social Security and Health requested that minor cellrisk analysis be conducted by the Intermutualistic Agency; this took place on 17 Aug 2016. Finally, approval was granted by the ethical committees at each of the eight participating hospitals.

Provenance and peer review Not commissioned; externally peer reviewed.

Data availability statement Data are available in a public, open-access repository. Data are available on reasonable request. Data may be obtained from a third party and are not publicly available. All data relevant to the study are included in the article or uploaded as online supplementary information.

Open access This is an open access article distributed in accordance with the Creative Commons Attribution Non Commercial (CC BY-NC 4.0) license, which permits others to distribute, remix, adapt, build upon this work non-commercially, and license their derivative works on different terms, provided the original work is properly cited, appropriate credit is given, any changes made indicated, and the use is non-commercial. See: http://creativecommons.org/licenses/by-nc/4.0/.

ORCID iD

Marie Friedel http://orcid.org/0000-0002-2681-8332

\section{REFERENCES}

1. Feudtner C, Christakis DA, Connell FA. Pediatric deaths attributable to complex chronic conditions: a population-based study of Washington state, 1980-1997. Pediatrics 2000;106:205-9.

2. Association for Children's Palliative Care and Royal College of Paediatrics and Child Health (ACT/RCPCH). A guide to the development of children's palliative care services. 1st edn. Bristol and London: ACT/RCPCH, 1997.

3. Abu-Saad Huijer H, Benini F, Craig F, et al. Steering Committee of the EAPC task force on palliative care for children and adolescents. IMPaCCT. Standards for paediatric palliative care in Europe. Eur $J$ Palliat Care 2017;14:109-14.

4. Connor SR, Downing J, Marston J. Estimating the global need for palliative care for children: a cross-sectional analysis. J Pain Symptom Manage 2017;53:171-7.

5. Fraser LK, Miller M, Hain R, et al. Rising national prevalence of life-limiting conditions in children in England. Pediatrics 2012;129:e923-9.

6. Jarvis S, Parslow RC, Carragher P, et al. How many children and young people with life-limiting conditions are clinically unstable? A national data linkage study. Arch Dis Child 2017;102:131-8.

7. Institut national de santé publique (INdSP). Soins palliatifs de fin de vie au Québec: Définition et mesure d'indicateurs. Partie 2: population pédiatrique (moins de 20 ans), 2008. Available: https:// www.inspq.qc.ca/pdf/publications/896_soinsPalPopPedFinal. pdf2008 [Accessed 5 Feb 2019].

8. Centre d'épidémiologie sur les causes médicales de décès CépiDC. INSERM 2008-issu du rapport 2011 de l'Observatoire national de la fin de vie: Fin de vie, un premier état des lieux. Chapitre 6: les soins palliatifs pédiatriques, 2011. Available: http://www.onfv.org/ 
wpcontent/uploads/2014/10/Rapport_ONFV_2011.pdf [Accessed 5 Feb 2019].

9. Håkanson C, Öhlén J, Kreicbergs $U$, et al. Place of death of children with complex chronic conditions: cross-national study of 11 countries. Eur J Pediatr 2017;176:327-35.

10. Jarvis S, Fraser LK. Comparing routine inpatient data and death records as a means of identifying children and young people with life-limiting conditions. Palliat Med 2018;32:543-53.

11. Belgian Ministry of Justice. Arrêté royal fixant les normes auxquelles la fonction "liaison pédiatrique" doit répondre pour être agréée, 2010. Available: http://www.ejustice.just.fgov.be/cgi/article_body. $\mathrm{pl}$ ?language $=$ fr\&caller $=$ summary\&pub_date $=10-12-30 \&$ numac $=$ 20100244592010 [Accessed 5 Feb 2019].

12. Belgian Ministry of Justice. Loi du 21 juillet 2016 modifiant la loi du 14 juin 2002 relative aux soins palliatifs en vue d'élargir la définition des soins palliatifs, 2016. Available: http://www.ejustice.just.fgov.be/cgi_ loi/loi_a.pl? =\&sql=(text+contains $+(\% 27 \% 27)) \&$ rech $=1$ \&language $=$ fr\& tri $=d d+A S+R A N K \&$ numero $=1 \&$ table name $=10 i \& F=\& c n=2002061446 \&$ caller=image_a1\&fromtab=loi\&la=F\&pdf_page $=8 \&$ pdf_file=http://www. ejustice.just.fgov.be/mopdf/2016/08/29_1.pdf [Accessed 5 Feb 2019].

13. Friedel M, Brichard B, Fonteyne $\mathrm{C}$, et al. Building bridges, paediatric palliative care in Belgium: a secondary data analysis of annual paediatric liaison team reports from 2010 to 2014. BMC Palliat Care 2018;17:77.
14. Feudtner C, Hays RM, Haynes G, et al. Deaths attributed to pediatric complex chronic conditions: national trends and implications for supportive care services. Pediatrics 2001;107:E99.

15. National Center for Health Statistics. International Classification of Diseases, Ninth Revision, Clinical Modification (ICD-9-CM). Available: https://www.cdc.gov/nchs/icd/icd9cm.htm [Accessed 5 Feb 2019].

16. eHealth. Service public Fédéral, Santé Publique, Sécurité de la chaîne alimentaire et environnement. Available: https://www.health. belgium.be/fr/sante/organisation-des-soins-de-sante/hopitaux/ systemes-denregistrement/rhm [Accessed 5 Feb 2019].

17. eHealth. Service public Fédéral, Santé Publique, Sécurité de la chaîne alimentaire et environnement. Available: https://www.ehealth. fgov.be/ehealthplatform/fr/mission [Accessed 5 Feb 2019].

18. Brussels Pluralist Federation for palliative and continuing care. Available: https://www.fbsp-bfpz.org/ [Accessed 5 Feb 2019].

19. Colloquium on paediatric palliative care in Brussels organised at the Brussels francophone, 2018. Available: https://docs.wixstatic.com/ ugd/b61916_ad2366a9e46e4abfa8e7db29c04bbf36.pdf

20. Hain R, Devins M, Hastings R, et al. Paediatric palliative care: development and pilot study of a 'Directory' of life-limiting conditions. BMC Palliat Care 2013;12:43. 